\title{
Registered report: Inhibition of BET recruitment to chromatin as an effective treatment for MLL-fusion leukemia
}

\section{Juan José Fung ${ }^{1}$, Alan Kosaka ${ }^{1}$, Xiaochuan Shan'ㄹ, Gwenn Danet-Desnoyers ${ }^{2}$, Michael Gormally ${ }^{3}$, Kate Owen ${ }^{4}$, Reproducibility Project: Cancer Biology*}

${ }^{1}$ ProNovus Bioscience, Mountain View, California; ${ }^{2}$ Stem Cell and Xenograft Core, University of Pennsylvania, Perelman School of Medicine, Philadelphia, Pennsylvania; ${ }^{3}$ University of Cambridge, Cambridge, United Kingdom; ${ }^{4}$ University of Virginia, Charlottesville, Virginia

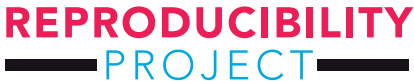
CANCER BIOLOGY

\author{
*For correspondence: \\ tim@cos.io \\ Group author details \\ Reproducibility Project: Cancer \\ Biology \\ See page 17 \\ Competing interests: \\ See page 17
}

Funding: See page 17

Received: 02 June 2015

Accepted: 04 August 2015

Published: 01 September 2015

Reviewing editor: Karen Adelman, National Institute of Environmental Health Sciences, United States

(c) Copyright Fung et al. This article is distributed under the terms of the Creative Commons Attribution License, which permits unrestricted use and redistribution provided that the original author and source are credited.
Abstract The Reproducibility Project: Cancer Biology seeks to address growing concerns about reproducibility in scientific research by conducting replications of selected experiments from a number of high-profile papers in the field of cancer biology. The papers, which were published between 2010 and 2012, were selected on the basis of citations and Altmetric scores (Errington et al., 2014). This Registered report describes the proposed replication plan of key experiments from 'Inhibition of bromodomain and extra terminal (BET) recruitment to chromatin as an effective treatment for mixed-lineage leukemia (MLL)-fusion leukemia' by Dawson and colleagues, published in Nature in 2011 (Dawson et al., 2011). The experiments to be replicated are those reported in Figures 2A, 3D, 4B, 4D and Supplementary Figures 11A-B and 16A. In this study, BET proteins were demonstrated as potential therapeutic targets for modulating aberrant gene expression programs associated with MLL-fusion leukemia. In Figure 2A, the BET bromodomain inhibitor I-BET151 was reported to suppress growth of cells harboring MLL-fusions compared to those with alternate oncogenic drivers. In Figure 3D, treatment of MLL-fusion leukemia cells with I-BET151 resulted in transcriptional suppression of the anti-apoptotic gene BCL2. Figures $4 B$ and $4 D$ tested the therapeutic efficacy of I-BET151 in vivo using mice injected with human MLL-fusion leukemia cells and evaluated disease progression following I-BET151 treatment. The Reproducibility Project: Cancer Biology is a collaboration between the Center for Open Science and Science Exchange and the results of the replications will be published in eLife.

DOI: 10.7554/eLife.08997.001

\section{Introduction}

The mixed-lineage leukemia $(M L L)$ gene encodes a large histone methyltransferase that directly binds DNA and positively regulates gene transcription (Marschalek, 2010). MLL is a frequent target of chromosomal translocation events (Meyer et al., 2009). During rearrangement, the N-terminus of MLL fuses to one of more than 60 partners, the most common of which coexist in a super elongation complex (SEC) enriched with transcription elongation factors (Meyer et al., 2009; Smith et al., 2011). The resulting fusion event converts $M L L$ into a potent transcriptional activator often giving rise to aggressive hematological malignancies (Mueller et al., 2009; Slany, 2009). The overall prognosis for pediatric and adult patients with confirmed MLL-fusion leukemia remains extremely poor and necessitates the development of new methodologies and therapeutic agents to improve survival outcomes (Slany, 2009; Tamai and Inokuchi, 2010).

Bromodomain and extra terminal (BET) proteins are transcriptional regulators that epigenetically control the expression of genes involved in cell cycle, growth and inflammation (Darnell, 2002; Wu and Chiang, 2007; LeRoy et al., 2008; Dey et al., 2009; Nicodeme et al., 2010). BETs therefore 
provide potential therapeutic targets for modulating gene expression programs associated with various human diseases. Dawson and colleagues identified novel interactions between BET family members bromodomain protein (BRD) 3 and BRD4 with components of the SEC and polymeraseassociated factor complexes in MLL fusion cells (Dawson et al., 2011). Given that BRD3 and BRD4 may be involved in the recruitment of the SEC and PAF complexes to regions of active chromatin, the authors tested the hypothesis that the dislocation of BET proteins from chromatin constitutes a viable therapeutic strategy in the treatment of MLL-fusion leukemia. For this purpose, Dawson and colleagues developed I-BET151, a BET inhibitor that selectively binds to the bromodomains of BET proteins and prevents their ability to bind acetylated histone residues (Dawson et al., 2011).

In Figure 2A and S11A-B, Dawson and colleagues assessed the ability of I-BET151 to suppress cell growth in a variety of human leukemia cell lines (Dawson et al., 2011). In these experiments, cells were treated with increasing concentrations of I-BET151 and allowed to grow for a further $72 \mathrm{hr}$. I-BET151 treatment was extremely effective at inhibiting the growth of leukemic cell lines harboring MLL fusions, including MV4;11, RS4;11, MOLM13, and NOMO1 cells, as determined by their low (nanomolar range) $\mathrm{IC}_{50}$ values. In contrast, the proliferation of cell lines using other oncogenic drivers, including gain-of-function kinase activity, was either resistant (K526) or significantly less sensitive (human erythroleukemic [HEL], HL60, and MEG01 cells) to I-BET151, exhibiting IC ${ }_{50}$ concentrations in the micromolar range and above. This key experiment shows that I-BET151 exhibits potent efficacy against MLL-fusion leukemic cell lines and will be replicated in Protocol 2. More recently, substantial growth inhibition with I-BET151 has been observed in other hematological malignancies, including acute myeloid leukemia (AML) (Dawson et al., 2014), multiple myeloma (MM) (Chaidos et al., 2014), and primary effusion lymphoma (Tolani et al., 2014), as well as non-hematological cancer models (medulloblastoma, melanoma, and glioblastoma) at concentrations ranging from 100 to $500 \mathrm{nM}$ (Gallagher et al., 2014; Long et al., 2014; Pastori et al., 2014). Additionally, the BET inhibitor JQ1 was reported to have a broad growth-suppressive activity, similar to I-BET151, effectively inhibiting leukemic cell lines, such as MV4;11, while K526 cells remained largely resistant (Zuber et alo, 2011).

To investigate the mechanism of action for I-BET151, Dawson and colleagues assessed apoptosis and cell cycle progression after drug treatment. Closer examination of the transcriptional pathways controlled by I-BET151 revealed that drug treatment repressed the activity of several known MLL targets, including the oncogene BCL-2. Bcl-2 promotes cell survival and protects cells from a wide range of cytotoxic insults (Cory et alo, 2003). In Figure 3D, the authors confirmed the ability of I-BET151 to transcriptionally downregulate BCL-2 expression in the MLL-fusion cell lines MOLM13, MV4;11, and NOMO1, but not in the K526 resistant cell line. This key experiment shows that I-BET151 is effective at silencing $B C L-2$ gene transcription and will be replicated in Protocol 3 . In addition to MLL-fusion cell lines, I-BET151 treatment correlated with enhanced apoptosis and reduced BCL-2 gene transcription in AML patient samples (Dawson et alo, 2014). In contrast, while I-BET151 also promoted cell death and/or growth inhibition in HEL cells (Wyspianska et al., 2014), Me1007 melanoma cells (Gallagher et al., 2014), and Sufu ${ }^{-1-}$ cells (mouse embryo fibroblasts deficient in the hedge hog signaling molecule Smoothened) (Long et al., 2014), drug treatment did not significantly impact Bcl-2 at either the gene or protein expression level.

In Figure 4B and 4D (and Supp. Figure 16A), the therapeutic potential of I-BET151 treatment was tested in vivo. Using a well-established model of disseminated MLL leukemia, animals were treated with I-BET151 21 days after transplantation with MV4;11 cells and monitored for clinical signs of disease. Here, Dawson and colleagues showed that I-BET151 significantly improved the length of disease-free survival and reduced evidence of peripheral blood (PB) disease compared to vehicletreated animals. Similar findings recapitulating the suppressive effect of I-BET151 on tumor growth have been reported in medulloblastoma, melanoma, and glioblastoma xenograft models (Gallagher et al., 2014; Long et al., 2014; Pastori et al., 2014). Similarly, follow-up studies by Dawson and colleagues demonstrated that I-BET151 confers a significant survival advantage and reduces the circulating leukemic burden in a murine model of AML (Dawson et al., 2014). These experiments will be replicated in Protocols 4 and 5. Similar studies testing the efficacy of JQ1, an independent BET inhibitor, reported a decrease in tumor growth in nude mice bearing AML xenografts (MV4;11 cells) (Mertz et al., 2011) and SCID-beige mice bearing MM xenografts (MM.1S cells) (Delmore et al., 2011). 


\section{Materials and methods}

\section{Protocol 1: Determine the population doubling time of K562 and MV4;11 cells}

The doubling time of K-562 and MV4;11 cells is assumed to be approximately 25 and $50 \mathrm{hr}$, respectively. To empirically determine the doubling time in the replicating lab, this general protocol will be used to determine the treatment time of K562 and MV4;11 cells for Protocol 2.

\section{Sampling}

- This experiment is performed with two cell lines (K562 and MV4;11).

- Each cell line to be performed with six technical repeats per experiment.

- The experiment is performed a total of once.

\section{Materials and reagents}

\begin{tabular}{|c|c|c|c|c|}
\hline Reagent & Type & Manufacturer & Catalog \# & Comments \\
\hline MV4;11 & Human cell line & ATCC & CRL-9591 & - \\
\hline K-562 & Human cell line & ATCC & CCL-243 & - \\
\hline $\begin{array}{l}\text { RPMI-1640 medium, with L-glutamine } \\
\text { and sodium bicarbonate }\end{array}$ & Cell culture reagent & Sigma-Aldrich & R8758 & Original catalog number not specified \\
\hline Fetal bovine serum (FBS) & Cell culture reagent & Sigma-Aldrich & $F 2442$ & Original brand not specified \\
\hline $\begin{array}{l}\text { Penicillin-streptomycin solution }(100 x) \\
\text { stabilized }\end{array}$ & Cell culture reagent & Sigma-Aldrich & P4333 & Original brand not specified \\
\hline T-75 flasks & Labware & Corning & $430641 \mathrm{U}$ & Original brand not specified \\
\hline $\begin{array}{l}\text { 96-well tissue culture plates (optically } \\
\text { clear) }\end{array}$ & Labware & Corning & 3595 & Original brand not specified \\
\hline $\begin{array}{l}\text { Cell-titer aqueous one solution cell } \\
\text { proliferation assay (MTS) }\end{array}$ & Assay kit & Promega & G3582 & - \\
\hline $\begin{array}{l}\text { Plate reader capable of reading } \\
\text { absorbance at } 490 \mathrm{~nm}\end{array}$ & Instrument & Molecular Devices & SpectraMax 190 & Replaces Gemini reader \\
\hline Softmax Pro & Software & Molecular Devices & Version 3.1 .2 & - \\
\hline
\end{tabular}

\section{Procedure}

\section{Note}

- All cells will be sent for mycoplasma testing and STR profiling.

- MV4;11 and K-562 human leukemic cells are maintained in RPMI-1640 medium supplemented with $10 \%$ fetal bovine serum (FBS) and $1 \%$ penicillin/streptomycin at $37^{\circ} \mathrm{C}$ with $5 \% \mathrm{CO}_{2}$.

1. Seed between $4 \times 10^{4}$ and $1 \times 10^{5}$ cells into two 96 -well tissue culture plates with $100 \mu$ of medium per well, excluding outer wells. Incubate cells overnight at $37^{\circ} \mathrm{C}$ with $5 \% \mathrm{CO}_{2}$.

a. Fill outer wells with medium alone.

b. Include six non-outer wells with medium alone for background subtraction.

2. With one plate perform MTS Assay (Promega CellTiter-Aqueous One) according to manufacturer's instructions.

a. Incubate plates for $4 \mathrm{hr}$ at $37^{\circ} \mathrm{C}$.

b. Read absorbance at $490 \mathrm{~nm}$.

c. Subtract background (average of medium only wells) from wells with cells and determine average reading from first plate.

3. 3 days later perform MTS Assay (Promega CellTiter-Aqueous One) according to manufacturer's instructions on second plate.

a. Incubate plates for $4 \mathrm{hr}$ at $37^{\circ} \mathrm{C}$.

b. Read absorbance at $490 \mathrm{~nm}$. 
c. Subtract background (average of medium only wells) from wells with cells and determine average reading from second plate.

4. Calculate the population doubling time for each cell line using the following formula:

a. Doubling time $=\ln 2 / \ln$ (second plate average reading/first plate average reading).

\section{Deliverables}

- Data to be collected:

O STR profile and result of mycoplasma testing.

Raw data and background subtracted absorbance at $490 \mathrm{~nm}$.

Confirmatory analysis plan

- n/a.

Known differences from the original study

All known differences are listed in the materials and reagents section above with the originally used item listed in the comments section. All differences have the same capabilities as the original and are not expected to alter the experimental design.

Provisions for quality control

The cell lines used in this experiment will undergo STR profiling to confirm their identity and will be sent for mycoplasma testing to ensure there is no contamination. All of the raw data will be uploaded to the project page on the OSF (https://osf.io/hcqqy) and made publically available.

\section{Protocol 2: Cell viability assay to determine selective inhibition of an MLL-fusion leukemic cell line with I-BET151}

This protocol assesses the ability of I-BET151, a small molecule inhibitor of BET family proteins, to selectively and potently inhibit the growth of the human leukemic cell line MV4;11, which is driven by an oncogenic translocation of the MLL gene. As a negative control, human K-562 leukemic cells, which are not oncogenically driven by an MLL-fusion, will also be treated with I-BET151. As a further negative control, both cell lines will be treated with vehicle alone (dimethyl sulfoxide (DMSO)). This protocol will replicate experiments reported in Figure 2A, Supp. Figure 11A, and Supp. Figure 11B.

\section{Sampling}

- This experiment will be performed three separate times (biological replicates) for a final power of $\geq 80 \%$. The original data reported a single $I_{50}$ value for each cell line, thus to determine an appropriate number of replicates to perform initially, sample sizes required based on a range of potential variance was determined. The sample size will also be determined post hoc as described in 'Power calculations' and additional replicates will be performed if necessary.

O See 'Power calculations' section for details.

- Experiment has two cohorts:

K562 human leukemic cells (-MLL).

O MV4;11 human leukemic cells (+MLL).

- Each cohort has 11 conditions to be performed in technical triplicate per experiment:

O DMSO (vehicle).

$0.01 \mathrm{nM}$ I-BET151.

O $0.1 \mathrm{nM}$ I-BET151.

O 1 nM I-BET151.

O 10 nM I-BET151.

O 100 nM I-BET151.

O $1 \mu \mathrm{M}$ I-BET151.

O $10 \mu \mathrm{M}$ I-BET151.

O $100 \mu \mathrm{M}$ I-BET151.

O 1 mM I-BET151.

O 10 mM I-BET151. 


\section{Materials and reagents}

\begin{tabular}{|c|c|c|c|c|}
\hline Reagent & Type & Manufacturer & Catalog \# & Comments \\
\hline MV4;11 & Human cell line & ATCC & CRL-9591 & - \\
\hline K-562 & Human cell line & ATCC & CCL-243 & - \\
\hline I-BET151 (GSK1210151A) & Small molecule & Sigma-Aldrich & SML0666 & - \\
\hline $\begin{array}{l}\text { RPMI- } 1640 \text { medium, with L-glutamine } \\
\text { and sodium bicarbonate }\end{array}$ & Cell culture reagent & Sigma-Aldrich & R8758 & Original catalog number not specified \\
\hline Fetal bovine serum (FBS) & Cell culture reagent & Sigma-Aldrich & $\mathrm{F} 2442$ & Original brand not specified \\
\hline $\begin{array}{l}\text { Penicillin-streptomycin solution (100x) } \\
\text { stabilized }\end{array}$ & Cell culture reagent & Sigma-Aldrich & P4333 & Original brand not specified \\
\hline T-75 flasks & Labware & Corning & $430641 \mathrm{U}$ & Original brand not specified \\
\hline $\begin{array}{l}\text { 96-well tissue culture plates (optically } \\
\text { clear) }\end{array}$ & Labware & Corning & 3595 & Original brand not specified \\
\hline $\begin{array}{l}\text { 96-well sterile plate (for preparing } \\
\text { compound dilutions) }\end{array}$ & Labware & Corning & 3370 & Original brand not specified \\
\hline DMSO, molecular biology grade & Reagent & Sigma-Aldrich & D8418 & Original brand not specified \\
\hline $\begin{array}{l}\text { Cell-titer aqueous one solution cell } \\
\text { proliferation assay (MTS) }\end{array}$ & Assay kit & Promega & G3582 & - \\
\hline $\begin{array}{l}\text { Plate reader capable of reading } \\
\text { absorbance at } 490 \mathrm{~nm}\end{array}$ & Instrument & Molecular Devices & SpectraMax 190 & Replaces Gemini reader \\
\hline Softmax Pro & Software & Molecular Devices & Version 3.1 .2 & - \\
\hline
\end{tabular}

\section{Procedure}

\section{Note}

- All cells will be sent for mycoplasma testing and STR profiling.

- MV4;11 and K-562 human leukemic cells maintained in RPMI-1640 medium, supplemented with $10 \%$ FBS and $1 \%$ penicillin/streptomycin at $37^{\circ} \mathrm{C}$ with $5 \% \mathrm{CO}_{2}$.

1. Seed between $4 \times 10^{4}$ and $1 \times 10^{5}$ cells into 96-well tissue culture plates with $90 \mu$ of medium per well, excluding outer wells. Incubate cells overnight at $37^{\circ} \mathrm{C}$ with $5 \% \mathrm{CO}_{2}$.

a. Fill outer wells with medium alone.

b. Include at least three non-outer wells with medium alone for background subtraction.

c. One plate for each cell line with 33 wells seeded with cells for each plate.

2. Treat cells with $10 \mu$ of $10 \times$ serial dilutions of I-BET151 to yield final dilutions of $0.01 \mathrm{nM}-10 \mathrm{mM}$ (10 dilutions), or treat with DMSO (vehicle) control.

a. Dilute stock of I-BET151 at 1000x final concentration of serial dilution stocks in DMSO (10 nM-10 M).

b. Dilute $1000 \times$ serial dilution stocks $1: 100$ in complete growth medium to yield a $10 \times$ stock

$(0.1 \mathrm{nM}-100 \mathrm{mM})$ that is added directly to the $90 \mu \mathrm{l}$ of cell/medium.

i. Final DMSO concentration kept to $0.1 \%$ DMSO.

3. Incubate cells for approximately three times the doubling time of each cell line.

a. The doubling time for each cell line is determined in Protocol 1.

4. Perform MTS Assay (Promega CellTiter-Aqueous One ${ }^{\circledR}$ ) according to manufacturer's instructions.

a. Incubate plates for $4 \mathrm{hr}$ at $37^{\circ} \mathrm{C}$.

b. Read absorbance at $490 \mathrm{~nm}$.

c. Calculate viability as a percentage of control (DMSO (vehicle) cells) after background subtraction.

5. Determine IC50 values for each cell line.

6. Repeat independently two additional times.

\section{Deliverables}

- Data to be collected:

O STR profile and result of mycoplasma testing of cells. 
O Raw absorbance data, I-BET151 values at each concentration normalized to DMSO-treated control values, and analyzed data (sigmoidal dose-response curves for I-BET151), and IC So values $_{5}$ determined for each cell line and repeat. (Compare to Figures S11A and S11B).

\section{Confirmatory analysis plan}

- Statistical analysis of the replication data:

O Unpaired two-tailed t-test of the IC $\mathrm{C}_{50}$ values for I-BET151 treated K-562 cells will be compared to $\mathrm{IC}_{50}$ values for I-BET151 treated MV4;11 cells.

- Meta-analysis of original and replication attempt effect sizes:

O The replication data (mean and $95 \%$ confidence interval) will be plotted with the original reported data value displayed as a single point on the same plot for comparison.

Known differences from the original study

All known differences are listed in the materials and reagents section above with the originally used item listed in the comments section. All differences have the same capabilities as the original and are not expected to alter the experimental design.

Provisions for quality control

The cell lines used in this experiment will undergo STR profiling to confirm their identity and will be sent for mycoplasma testing to ensure there is no contamination. The doubling time of each cell line was determined in Protocol 1. All of the raw data will be uploaded to the project page on the OSF (https://osf.io/hcqqy) and made publically available.

\section{Protocol 3: qPCR analysis of BCL2 gene expression following I-BET151 treatment}

This protocol evaluates the expression of the BCL2 gene in both MV4;11 (+MLL) and K-562 (-MLL) leukemic cell lines following treatment with the BET inhibitor I-BET151. BCL2 is a key anti-apoptotic gene implicated in the pathogenesis of MLL-fusion leukemias. Treatment with I-BET151 is expected to reduce the expression of $B C L 2$ in MV4;11 cells, but not in the unresponsive K-562 cells. As a control, both cell lines will also be treated with vehicle alone (DMSO only). The expression of BCL2 will be normalized against the endogenous expression of $\beta_{2}$ microglobulin (B2M). This protocol will replicate experiments reported in Figure 3D.

\section{Sampling}

- Perform this experiment three separate times (biological replicates) for a minimum power of $80 \%$. See 'Power calculations' section for details.

- Experiment has two cohorts: O K562 human leukemic cells (-MLL). O MV4;11 human leukemic cells (+MLL).

- Each cohort has two conditions to be performed in technical duplicate per experiment (qRT-PCR of $B C L 2$ and B2M):

O DMSO (vehicle).

O 500 nM I-BET151.

Materials and reagents

\begin{tabular}{lllll} 
Reagent & Type & Manufacturer & Catalog \# & Comments \\
\hline MV4;11 & Human cell line & ATCC & CRL-9591 & - \\
\hline K-562 & Human cell line & ATCC & CCL-243 & - \\
\hline I-BET151 (GSK1210151A) & Small molecule & Sigma-Aldrich & SML0666 & - \\
\hline DMSO, molecular biology grade & Reagent & Sigma-Aldrich & D8418 & Original brand not specified \\
\hline $\begin{array}{l}\text { RPMI-1640 medium, with L-glutamine } \\
\text { and sodium bicarbonate }\end{array}$ & Cell culture reagent & Sigma-Aldrich & R8758 & Original catalog number not specified
\end{tabular}

Continued on next page 
Continued

\begin{tabular}{|c|c|c|c|c|}
\hline Reagent & Type & Manufacturer & Catalog \# & Comments \\
\hline Fetal bovine serum (FBS) & Cell culture reagent & Sigma-Aldrich & F2442 & Original brand not specified \\
\hline $\begin{array}{l}\text { Penicillin-streptomycin solution (100x) } \\
\text { stabilized }\end{array}$ & Cell culture reagent & Sigma-Aldrich & P4333 & Original brand not specified \\
\hline 48-well tissue culture plates & Labware & Corning & 3548 & Original brand not specified \\
\hline RNAspin mini & RNA isolation & Sigma-Aldrich & GE25-0500-70 & $\begin{array}{l}\text { Replaces Qiagen cat. no. } 74104 \text { used in } \\
\text { original study }\end{array}$ \\
\hline Nuclease-free water (DEPC-treated) & Chemical & Sigma-Aldrich & 95284 & Reagent needed for RNAspin Mini protocol \\
\hline 96-well plates (for quantification of RNA) & Labware & Corning & 3635 & $\begin{array}{l}\text { UV/Vis 96-well clear plates for use on } \\
\text { Molecular Devices Spectramax } 190\end{array}$ \\
\hline First-strand cDNA synthesis kit & cDNA synthesis & Sigma-Aldrich & GE27-9261-01 & $\begin{array}{l}\text { Replaces Invitrogen cat. no. } 28025-013 \text { used } \\
\text { in original study }\end{array}$ \\
\hline BCL2-primers (forward and reverse) & Nucleic acid & \multirow{2}{*}{\multicolumn{3}{|c|}{$\begin{array}{l}\text { Sequences listed below in procedure; specific brand information will be left up to the } \\
\text { discretion of the replicating lab and recorded later }\end{array}$}} \\
\hline B2M-primers (forward and reverse) & Nucleic acid & & & \\
\hline 96-well multiplate PCR plates, clear & qPCR & Bio-Rad & MLL9601 & Original brand not specified \\
\hline qPCR plate seals & Labware & Bio-Rad & MSB1001 & $\begin{array}{l}\text { Or equivalent optically clear seals will be } \\
\text { used }\end{array}$ \\
\hline $\mathrm{SYBR}^{\circledR}$ green PCR master mix & qPCR & Life Technologies & 4344463 & - \\
\hline DNA engine opticon system (qRT-PCR) & Instrument & Bio-Rad & $\mathrm{n} / \mathrm{a}$ & Replaces ABI 7900 \\
\hline Opticon monitor & Software & Bio-Rad & $\mathrm{n} / \mathrm{a}$ & - \\
\hline
\end{tabular}

\section{Procedure}

Note

- All cells will be sent for mycoplasma testing and STR profiling.

- MV4;11 and K-562 human leukemic cells maintained in RPMI-1640 medium, supplemented with 10\% FBS and $1 \%$ penicillin/streptomycin at $37^{\circ} \mathrm{C}$ with $5 \% \mathrm{CO}_{2}$.

1. Seed MV4;11 or K-562 cells into 48 -well tissue culture plates at $8 \times 10^{4}$ to $2 \times 10^{5}$ cells per well in triplicate. Incubate cells overnight at $37^{\circ} \mathrm{C}$ with $5 \% \mathrm{CO}_{2}$.

2. Treat cells with DMSO or $500 \mathrm{nM} \mathrm{I-BET151} \mathrm{for} 6 \mathrm{hr}$, in triplicate.
a. Add drug directly to each well.
b. Make stocks of I-BET151 at 1000x stock $(500 \mu \mathrm{M})$ in DMSO.
c. Final DMSO concentration kept to $0.1 \%$.

3. Harvest cells and isolate RNA using the RNAspin mini kit according to manufacturer's instructions. a. Determine RNA purity $\left(\mathrm{A}_{260 / 280}\right.$ and $\mathrm{A}_{260 / 230}$ ratios) and concentration.

4. Prepare cDNA using SuperScript III First-Strand Synthesis System according to the manufacturer's instructions.

5. Perform semi-quantitative $P C R$ reactions, in triplicate, using BCL2-specific primers, B2M-specific primers (for normalization), and SYBR green PCR mastermix according to the manufacturer's instructions.

a. Primers:
i. BCL2 forward: AGTACCTGAACCGGCACCT.
ii. BCL2 reverse: CAGCCAGGAGAAATCAAACAG.
iii. B2M forward: TGACTTTGTCACAGCCCAAG.
iv. B2M reverse: AGCAAGCAAGCAGAATTTGG.

6. Analyze data using the $\triangle \triangle C_{T}$ method: First, normalize $B C L 2$ values to $B 2 M$ (housekeeping) values. Next, normalize I-BET151-treated cells to DMSO-treated cells to determine fold change of treatment relative to DMSO.

7. Repeat independently two additional times.

\section{Deliverables}

- Data to be collected: 
O STR profile and result of mycoplasma testing of cells.

$O$ Purity $\left(A_{260 / 280}\right.$ and $A_{260 / 230}$ ratios) and concentration of isolated total RNA from cells.

$O$ Raw qRT-PCR values, as well as analyzed $\Delta \Delta C_{T}$ values and bar graph of BCL2 mRNA normalized to control mRNA levels for each condition. (Compare to Figure 3D).

\section{Confirmatory analysis plan}

- Statistical analysis of the replication data:

O Two-tailed $t$-tests with the Bonferroni correction:

- Unpaired two-sample t-test of $\Delta \Delta \mathrm{C}_{\mathrm{T}}$ values from $\mathrm{K} 562$ cells compared to MV4;11 cells.

- One-sample t-test of $\Delta \Delta \mathrm{C}_{\mathrm{T}}$ values from $\mathrm{K} 562$ cells compared to a constant of 1 .

- One-sample t-test of $\Delta \Delta \mathrm{C}_{\mathrm{T}}$ values from MV4;11 cells compared to a constant of 1 .

- Meta-analysis of effect sizes:

Compute the effect sizes of each comparison, compare them against the effect size in the original paper and use a random effects meta-analytic approach to combine the original and replication effects, which will be presented as a forest plot.

Known differences from the original study

All known differences are listed in the materials and reagents section above with the originally used item listed in the comments section. All differences have the same capabilities as the original and are not expected to alter the experimental design.

Provisions for quality control

The cell lines used in this experiment will undergo STR profiling to confirm their identity and will be sent for mycoplasma testing to ensure there is no contamination. All of the raw data will be uploaded to the project page on the OSF (https://osf.io/hcqqy) and made publically available.

\section{Protocol 4: Assessment of maximum tolerable dose of I-BET151 in xenograft AML mouse model}

This protocol assesses the maximum tolerable dose (MTD) of I-BET151 in a xenograft mouse model of leukemia by intra-peritoneal injection, using a range of I-BET151 compound. The original study reported using $30 \mathrm{mg} / \mathrm{kg} /$ day, however, as batch-to-batch variation occurs, the MTD will be assessed in this protocol to avoid toxicity. The MTD determined in this protocol will be used in Protocol 5 to assess the efficiency of I-BET151 in this model.

\section{Sampling}

- Experiment has four cohorts:

O Cohort 1: NOD/SCID mice treated daily with vehicle only.

O Cohort 2: NOD/SCID mice treated daily with $10 \mathrm{mg} / \mathrm{kg} /$ day I-BET151.

O Cohort 3: NOD/SCID mice treated daily with $20 \mathrm{mg} / \mathrm{kg} /$ day I-BET151.

O Cohort 4: NOD/SCID mice treated daily with 30 mg/kg/day I-BET151.

- Experiment will use five mice per treatment group.

O See 'Power calculations' section for details.

Materials and reagents

\begin{tabular}{lllll} 
Reagent & Type & Manufacturer & Catalog \# & Comments \\
\hline MV4;11 & Human cell line & ATCC & CRL-9591 & - \\
\hline I-BET151 (GSK1210151A) & Small molecule & Sigma-Aldrich & SML0666 & - \\
\hline DMSO, molecular biology grade & Reagent & Sigma-Aldrich & D1435 & Original brand not specified \\
\hline $\begin{array}{l}\text { RPMI-1640 medium, with L-glutamine } \\
\text { and sodium bicarbonate }\end{array}$ & $\begin{array}{l}\text { Cell culture } \\
\text { reagent }\end{array}$ & Gibco, Life Technologies & 22400-089 & $\begin{array}{l}\text { Original catalog number not } \\
\text { specified }\end{array}$ \\
\hline Fetal bovine serum (FBS) & $\begin{array}{l}\text { Cell culture } \\
\text { reagent }\end{array}$ & Sigma-Aldrich & F2442 & Original brand not specified \\
\hline
\end{tabular}


Continued

\begin{tabular}{|c|c|c|c|c|}
\hline Reagent & Type & Manufacturer & Catalog \# & Comments \\
\hline $\begin{array}{l}\text { Penicillin-streptomycin solution } \\
(100 \times) \text { stabilized }\end{array}$ & $\begin{array}{l}\text { Cell culture } \\
\text { reagent }\end{array}$ & Invitrogen & 15140122 & Original brand not specified \\
\hline Phosphate buffered saline (PBS) & Buffer & Gibco, Life Technologies & $14190-136$ & - \\
\hline $\begin{array}{l}\text { Female and male NOD-SCID mice } \\
\text { (6-8 weeks old) }\end{array}$ & Animal model & Jackson Laboratory & 001303 & - \\
\hline IV Busulfex (busulfan) & Chemical & $\begin{array}{l}\text { Otsuka America } \\
\text { Pharmaceutical, Inc. }\end{array}$ & $\begin{array}{l}\text { NDC 59148- } \\
070-90\end{array}$ & Not originally used \\
\hline $\begin{array}{l}1 / 2 \text { cc LO-DOSE U-100 insulin } \\
\text { syringe } 28 G\end{array}$ & Labware & Becton-Dickinson & 329461 & Original brand not specified \\
\hline APC anti-human HLA-A,B,C antibody & Antibodies & Biolegend & 311410 & $\begin{array}{l}\text { Original catalog number not } \\
\text { specified }\end{array}$ \\
\hline $\begin{array}{l}\text { APC mouse lgG2a, кisotype control } \\
\text { antibody }\end{array}$ & Antibodies & Biolegend & 400220 & - \\
\hline Kleptose HPB & Chemical & Roquette Pharma & $\mathrm{n} / \mathrm{a}$ & Original brand not specified \\
\hline $0.9 \% \mathrm{NaCl}, \mathrm{USP}$ & Chemical & Hospira, Inc & 0490-1966-05 & Original brand not specified \\
\hline 1cc insulin syringe U-100 27G 5/8 & Labware & Becton-Dickinson & 329412 & Original brand not specified \\
\hline Flow cytometer & Instrument & Becton-Dickinson & $\mathrm{n} / \mathrm{a}$ & $\begin{array}{l}\text { Canto or LSR II (replaces CyAn ADP } \\
\text { from Dako) }\end{array}$ \\
\hline FlowJo software & Software & Tree Star, Inc & $\mathrm{n} / \mathrm{a}$ & - \\
\hline
\end{tabular}

\section{Procedure}

Note

- All cells will be sent for mycoplasma testing and STR profiling, as well as screened against a Rodent Pathogen Panel.

- MV4;11 human leukemic cells maintained in RPMI-1640 medium, supplemented with $10 \%$ FBS and $1 \%$ penicillin/streptomycin at $37^{\circ} \mathrm{C}$ with $5 \% \mathrm{CO}_{2}$.

1. Receive non-obese diabetic/severely compromised immunodeficient (NOD-SCID) female and male mice (6-8 weeks old).

a. An equal number of male and female mice should be used.

b. Allow animals 1 week to acclimatize in a pathogen-free enclosure before start of study.

c. Animals are housed in sterile conditions using high-efficiency particulate arrestance (HEPA)-filtered microisolator with 12-hr light/dark cycles, and fed with sterile rodent chow and acidified water ad libitum.

2. Condition mice with $30 \mathrm{mg} / \mathrm{kg}$ busulfan by intraperitoneal injection $24 \mathrm{hr}$ prior to injection of MV4; 11 cells.

3. Intravenously inject $1 \times 10^{7} \mathrm{MV} 4 ; 11$ cells in $0.2 \mathrm{ml}$ sterile vehicle (PBS) into the tail vein of conditioned mice.

4. Monitor mice for engraftment:

a. Inspect mice daily for signs of distress and record the scores using the 'Mouse Health Scoring System' (Supplementary file 1) for 21 days (Cooke et al., 1996).

b. Weigh mice weekly for the entire duration of the experiment.

c. At day 21 post-injection, collect retro-orbital bleeds and analyze leukemia burden (percent human HLA-A,B, $C^{+}$cells) by flow cytometry.

i. Stain samples with the following antibodies following manufacturer's recommendations:

1. APC conjugated anti-human HLA-A,B,C.

2. APC conjugated isotype control.

ii. Perform flow cytometric analysis following manufacturer's instructions.

iii. Gating strategy:

1. On SSC vs FSC plot, gate on total nucleated population (both mouse and human cells).

2. From the nucleated population, gate on HLA-A,B,C+ cells (human leukemia cells).

5. Randomize mice into four cohorts using the following method:

a. Exclude mice with no detectable leukemia burden.

i. Use $0.5 \%$ human leukemia cells (HLA-A,B, $C^{+}$cells) over the total live nucleated cells (human and mouse cells) in sample as a minimum threshold of engraftment (leukemia detected). 
b. Animals are randomized according to a stratified randomization procedure to balance gender and baseline tumor characteristics.

i. Female and male mice are assigned into separate blocks.

ii. In each block, animals are ranked according to disease burden (percent human HLA-A,B, $C^{+}$ cells) and group assignment is performed with a simple randomization procedure.

6. Begin once daily intraperitoneal injections with vehicle control, $10 \mathrm{mg} / \mathrm{kg}$ I-BET151, $20 \mathrm{mg} / \mathrm{kg}$ I-BET151, or $30 \mathrm{mg} / \mathrm{kg} \mathrm{I-BET151} \mathrm{(dose} \mathrm{volume} \mathrm{is} 10 \mathrm{ml} / \mathrm{kg}$ ).

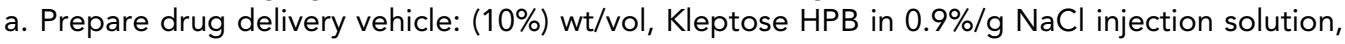
$\mathrm{pH}$ 5.0.

i. Weigh required amount of Kleptose HPB into a suitable glass container, for example, volumetric flask.

ii. Make up to a final volume with $0.9 \% / \mathrm{g}$ saline to achieve a $10 \%$ wt/vol, Kleptose HPB solution. iii. Mix contents until vehicle has visually clarified.

b. Prepare initial formulation of I-BET151: $60 \mathrm{mg} / \mathrm{ml}$ of I-BET151 in DMSO (stock).

i. Dispense the DMSO into the compounding vessel containing I-BET151.

ii. Gently mix for minimum of 2 min or until complete dissolution achieved.

c. Prepare the final drug formulation composition: 1, 2, or $3 \mathrm{mg} / \mathrm{ml}$ of I-BET151 in 5:95 vol/vol DMSO: drug delivery vehicle.

i. Make a 20-fold dilution of the I-BET151 stock with the drug delivery vehicle; adjust $\mathrm{pH}$ to 5.0 using $2 \mathrm{M} \mathrm{HCl}$ to obtain a $3 \mathrm{mg} / \mathrm{ml} \mathrm{l-BET151}$ injection solution.

1. Dispense the DMSO stock into a glass recipient vessel containing $25 \mathrm{ml}$ of the required volume of vehicle.

2. With the remaining $4.925 \mathrm{ml}$ of vehicle, rinse the vessel containing the DMSO stock, adding the rinsed volume to the compounding vessel from step 1, removing any remaining dose by pipette.

3. Gently mix for minimum of $1 \mathrm{~min}$. A cloudy dose should form.

4. Accurately add $2 \mu \mathrm{l}$ of $2 \mathrm{M} \mathrm{HCl}$ to the compounding vessel by use of pipette.

5. Gently mix for minimum of $1 \mathrm{~min}$.

6. Repeat steps 4 and 5 as required until a clear solution is formed.

7. Take $\mathrm{pH}$ of resultant solution (final $\mathrm{pH}$ should be 5.0 ).

ii. Make a 1.5-fold dilution of the $3 \mathrm{mg} / \mathrm{ml} \mathrm{I-BET151} \mathrm{injection} \mathrm{solution} \mathrm{with} \mathrm{the} \mathrm{drug} \mathrm{delivery}$ vehicle to obtain a $2 \mathrm{mg} / \mathrm{ml} \mathrm{l-BET151}$ injection solution.

iii. Make a two-fold dilution of the $3 \mathrm{mg} / \mathrm{ml} \mathrm{I-BET151} \mathrm{injection} \mathrm{solution} \mathrm{with} \mathrm{the} \mathrm{drug} \mathrm{delivery}$

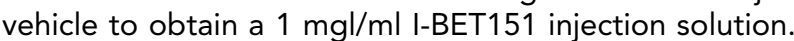

d. Sub aliquot into fresh glass vials for use during the duration of the study.

i. Make 21 aliquots for each injection solution $(3 \mathrm{mg} / \mathrm{ml}, 2 \mathrm{mg} / \mathrm{ml}$, and $1 \mathrm{mg} / \mathrm{ml})$ at $1.8 \mathrm{ml} / \mathrm{vial}$.

ii. Store at $4^{\circ} \mathrm{C}$.

1. Dose stability has been determined for 21 days following storage at $+4^{\circ} \mathrm{C}$. If study duration is longer than 21 days another dose would need to be prepared on day 22.

e. Bring one aliquot of each injection solution $(3 \mathrm{mg} / \mathrm{ml}, 2 \mathrm{mg} / \mathrm{ml}$, and $1 \mathrm{mg} / \mathrm{ml}$ ) to room temperature before injection.

7. Continue dosing mice with either drug or vehicle every day for 21 days.

a. Monitor mice daily for signs of disease (activity, posture, fur texture, and mobility).

b. Weigh mice once a week.

c. Record scores according to the 'Mouse Health Scoring System' (see step 4a).

d. Euthanize mice when they receive a heath monitoring score of 3 . This includes early signs of loss of hind limb motility, which is indicative of this disease model (O'Farrell et al., 2003; Lopes de Menezes et al., 2005).

e. Euthanize all remaining mice within 3 days of the last treatment.

8. The MTD will be determined by identifying the dose at which the group body weight loss does not exceed $20 \%$ compared with the vehicle group and at which morbidity is not observed in one or more animals. When the MTD is reached, the next lowest dose will be used in Protocol 5.

\section{Deliverables}

- Data to be collected:

O STR profile and result of mycoplasma and pathogen testing of cells.

O Mouse health records (health monitoring [scores 0-3], weekly animal weights, date of treatment, euthanasia, and cause of termination).

O Kaplan-Meier survival curves by group. 
All flow cytometry plots in gating scheme (including controls), leading to final populations of $\mathrm{HLA}-\mathrm{A}, \mathrm{B}, \mathrm{C}^{+}$cells before treatment intervention.

Confirmatory analysis plan

- $\mathrm{n} / \mathrm{a}$.

Known differences from the original study

The original study conditioned the recipient mice with a sublethal dose of radiation (300 cGy) prior to injection of MV4;11 cells. The replication attempt will use a single dose of busulfan, which has been reported to be comparable for human cell engraftment in NOD-SCID mice (Robert-Richard et al., 2006). All known differences are listed in the materials and reagents section above with the originally used item listed in the comments section. All differences have the same capabilities as the original and are not expected to alter the experimental design.

Provisions for quality control

The cell lines used in this experiment will undergo STR profiling to confirm its identity and will be sent for mycoplasma testing to ensure there is no contamination. Additionally, cells used for xenograft injection will be screened against a Rodent Pathogen Panel to ensure no contamination prior to injection. The animals will be randomized prior to treatment. All of the raw data will be uploaded to the project page on the OSF (https://osf.io/hcqqy) and made publically available.

\section{Protocol 5: Generation of disseminated xenograft AML mouse model and testing of I-BET151 compound in vivo}

This protocol assesses the efficacy of I-BET151 as a therapeutic agent in a xenograft mouse model of leukemia. Immunocompromised mice will be injected with preparations of MV4;11 cells and disease will progress for 21 days. At day 21, mice will be treated either with I-BET151 or vehicle control. Disease-free progression will be measured and plotted, as reported in Figure 4B. The presence and degree of disease progression will be determined by measuring the number of human leukemia cells present in the PB, spleen, and bone marrow (BM) of leukemic xenograft mice. Leukemic mice treated with I-BET151 will be compared to mice treated with vehicle control. This protocol replicates the experiments reported in Figure 4D and Supp. Figure 16A.

\section{Sampling}

- Experiment has two cohorts:

O NOD/SCID mice treated daily with vehicle only.

O NOD/SCID mice treated daily with dose of I-BET151 determined in Protocol 4.

- Experiment will use 14 mice per treatment group.

$\bigcirc$ To account for a higher censor rate, or exclusion, 14 mice will be used per group to ensure enough mice are included to reach a minimum power of $80 \%$.

O See 'Power calculations' section for details.

Materials and reagents

\begin{tabular}{lllll} 
Reagent & Type & Manufacturer & Catalog \# & Comments \\
\hline MV4;11 & Human cell line & ATCC & CRL-9591 & - \\
\hline I-BET151 (GSK1210151A) & Small molecule & Sigma-Aldrich & SML0666 & - \\
\hline DMSO, molecular biology grade & Reagent & Sigma-Aldrich & D1435 & Original brand not specified \\
\hline $\begin{array}{l}\text { RPMI-1640 medium, with L- } \\
\text { glutamine and sodium bicarbonate }\end{array}$ & Cell culture reagent & Gibco, Life Technologies & $22400-089$ & Original catalog number not \\
specified
\end{tabular}

Continued on next page 
Continued

\begin{tabular}{|c|c|c|c|c|}
\hline Reagent & Type & Manufacturer & Catalog \# & Comments \\
\hline $\begin{array}{l}\text { Female and male NOD-SCID mice } \\
\text { (6-8 weeks old) }\end{array}$ & Animal model & Jackson Laboratory & 001303 & - \\
\hline IV Busulfex (busulfan) & Chemical & $\begin{array}{l}\text { Otsuka America } \\
\text { Pharmaceutical, Inc. }\end{array}$ & $\begin{array}{l}\text { NDC 59148- } \\
070-90\end{array}$ & Not originally used \\
\hline Ammonium chloride solution & Chemical & Stem Cell Technologies & 07850 & $\begin{array}{l}\text { Replaces red blood cell lysis buffer } \\
\text { from } 5 \text { prime }\end{array}$ \\
\hline $\begin{array}{l}\text { CountBright absolute counting } \\
\text { beads }\end{array}$ & $\begin{array}{l}\text { Flow cytometry } \\
\text { reagent }\end{array}$ & Life Technology & C36950 & Not originally used \\
\hline FACS lysing solution & Chemical & Becton-Dickinson & 349202 & $\begin{array}{l}\text { Replaces red blood cell lysis buffer } \\
\text { from } 5 \text { prime }\end{array}$ \\
\hline $\begin{array}{l}1 / 2 \text { cc LO-DOSE U-100 insulin } \\
\text { syringe } 28 G\end{array}$ & Labware & Becton-Dickinson & 329461 & Original brand not specified \\
\hline $\begin{array}{l}\text { APC anti-human HLA-A,B,C } \\
\text { antibody }\end{array}$ & Antibodies & Biolegend & 311410 & $\begin{array}{l}\text { Original catalog number not } \\
\text { specified }\end{array}$ \\
\hline $\begin{array}{l}\text { APC mouse lgG2a, } \kappa \text { isotype control } \\
\text { antibody }\end{array}$ & Antibodies & Biolegend & 400220 & - \\
\hline Annexin V-FITC Kit & Antibodies & Miltenyi Biotec Ltd & $130-092-052$ & $\begin{array}{l}\text { Original catalog number not } \\
\text { specified }\end{array}$ \\
\hline 7-AAD & Dye & BD Pharmingen & $51-68981 E$ & $\begin{array}{l}\text { Original catalog number not } \\
\text { specified }\end{array}$ \\
\hline Kleptose HPB & Chemical & Roquette Pharma & $\mathrm{n} / \mathrm{a}$ & Original brand not specified \\
\hline $0.9 \% \mathrm{NaCl}, \mathrm{USP}$ & Chemical & Hospira, Inc & 0490-1966-05 & Original brand not specified \\
\hline 1cc insulin syringe U-100 27G 5/8 & Labware & Becton-Dickinson & 329412 & Original brand not specified \\
\hline Flow cytometer & Instrument & Becton-Dickinson & $\mathrm{n} / \mathrm{a}$ & $\begin{array}{l}\text { Canto or LSR II (replaces CyAn ADP } \\
\text { from Dako) }\end{array}$ \\
\hline FlowJo software & Software & Tree Star, Inc & $\mathrm{n} / \mathrm{a}$ & - \\
\hline
\end{tabular}

\section{Procedure}

\section{Note}

- All cells will be sent for mycoplasma testing and STR profiling, as well as screened against a Rodent Pathogen Panel.

- MV4;11 human leukemic cells maintained in RPMI-1640 medium, supplemented with 10\% FBS and $1 \%$ penicillin/streptomycin at $37^{\circ} \mathrm{C}$ with $5 \% \mathrm{CO}_{2}$.

1. Receive female and male NOD-SCID mice (6-8 weeks old).

a. An equal number of male and female mice should be used.

b. Allow animals 1 week to acclimatize in a pathogen-free enclosure before start of study.

c. Animals are housed in sterile conditions using HEPA-filtered micro-isolator with 12-hr light/dark cycles, and fed with sterile rodent chow and acidified water ad libitum.

2. Condition mice with $30 \mathrm{mg} / \mathrm{kg}$ busulfan by intraperitoneal injection $24 \mathrm{hr}$ prior to injection of MV4;11 cells.

3. Intravenously inject $1 \times 10^{7} \mathrm{MV} 4 ; 11$ cells in $0.2 \mathrm{ml}$ sterile vehicle (PBS) into the tail vein of conditioned mice.

4. Monitor mice for engraftment as described in step 4 of Protocol 4.

5. Randomize mice into four cohorts using the following method.

a. Exclude mice with no detectable leukemia burden.

i. Use $0.5 \%$ human leukemia cells (HLA-A, $B, C^{+}$cells) over the total live nucleated cells (human and mouse cells) in sample as a minimum threshold of engraftment (leukemia detected).

b. Animals are randomized according to a stratified randomization procedure to balance gender and baseline tumor characteristics.

i. Female and male mice are assigned into separate blocks.

ii. In each block, animals are ranked according to disease burden (percent human HLA-A, B, C+ cells) and group assignment is performed with a simple randomization procedure. 
6. Begin once daily intraperitoneal injections with vehicle control or I-BET151 dose determined from Protocol 4 (dose volume is $10 \mathrm{ml} / \mathrm{kg}$ ).

a. Prepare vehicle and drug as outlined in step 6 of Protocol 4.

b. The same lot of I-BET151 will be used.

7. Continue dosing mice with either drug or vehicle every day for 21 days.

a. Monitor mice as described in step 7 of Protocol 4.

b. Euthanize mice when they receive a health-monitoring score of 3 or within 3 days of the last treatment.

8. At sacrifice, collect PB by cardiac puncture into EDTA-treated tubes. Remove spleen and both tibias and femurs per mouse.

a. Prepare cell suspensions from spleen (SPL) by pressing the spleen through a cell strainer in PBS and BM cells by flushing both tibias and femurs with PBS following the replicating lab's standard protocols.

b. For HLA-A,B,C and apoptosis analysis (step 9 below), lyse red blood cells from samples using ammonium chloride solution following manufacturer's instructions.

c. Collect two equal aliquots of cells for HLA-A,B,C and apoptosis analysis (step 9 below) and leukemia burden (step 10 below).

9. Perform flow cytometric analysis for apoptosis analysis in PB, SPL, and BM cells using Annexin V-FITC kit.

a. Stain no more than $1 \times 10^{6}$ cells per sample with the following antibodies according to manufacturer's recommendations in PBS supplemented with $0.1 \%$ bovine serum albumin and 1 mM EDTA.

i. APC conjugated anti-human HLA-A,B,C with 7-AAD and Annexin V-FITC.

ii. APC conjugated isotype control with 7-AAD and Annexin V-FITC.

b. Gating strategy:

i. On FSC vs HLA-A,B,C plot, gate on HLA-A, $B, C^{+}$cells (human leukemia cells).

ii. From the leukemia cell population, use Annexin $V$ vs 7-AAD plot to gate on the following cell populations:

1. Annexin ${ }^{+} 7-A A D^{-}$population (apoptotic cells).

2. Annexin ${ }^{+}$7-AAD ${ }^{+}$population (dead cells).

10. Perform flow cytometry analysis for leukemia burden in $P B, S P L$, and BM cells.

a. Stain PB, SPL, and BM cells in a sample volume of $50 \mu$ leach. Add $20 \mu$ of the following antibodies and incubate at room temperature for $15 \mathrm{~min}$.

i. APC conjugated anti-human HLA-A,B,C.

ii. APC conjugated isotype control.

b. Add CountBright absolute counting beads in 1x FACS lysing solution and incubate at room temperature for $15 \mathrm{~min}$.

c. Perform flow cytometric analysis following manufacturer's instructions.

d. Gating strategy:

i. On the FL3-H vs FSC plot, gate on CountBright absolute counting beads.

ii. On SSC vs FSC plot, gate on total nucleated population (both mouse and human cells).

iii. From the nucleated population, use HLA-A,B,C vs SSC plot to gate on HLA-A, $B, C^{+}$cells (human leukemia cells).

11. For each mouse, confirm the presence or absence of leukemia. If a mouse is euthanized before the end of the experiment time length, but does not have detectable disease as assessed by flow cytometry, they should be censored from the Kaplan-Meier survival curve.

a. Use $0.5 \%$ human leukemia cells (HLA-A, $B, C^{+}$cells) over the total live nucleated cells (human and mouse cells) in sample as a minimum threshold of engraftment (leukemia detected).

\section{Deliverables}

- Data to be collected:

O STR profile and result of mycoplasma and pathogen testing of cells.

Mouse health records (health monitoring (scores 0-3), weekly animal weights, date of treatment, euthanasia, and cause of termination).

Kaplan-Meier survival curve comparing disease-free survival of I-BET151-treated xenografted mice vs vehicle-treated control xenografted mice. Compare to Figure 4B.

$O$ Include raw disease-free survival data for I-BET151 treated and untreated xenografted mice, including any mice censored because of no detectable disease. 
All flow cytometry plots in gating scheme (including controls), leading to final populations of $\mathrm{HLA}-\mathrm{A}, \mathrm{B}, \mathrm{C}^{+}$cells before and after treatment intervention. Compare to Figure $4 \mathrm{D}$ and Supplemental Figure S16A.

Number of $\mathrm{HLA}-\mathrm{A}, \mathrm{B}, \mathrm{C}^{+}$cells in $\mathrm{PB}, \mathrm{SPL}$, and $\mathrm{BM}$ in each treatment group.

Confirmatory analysis plan

- Statistical analysis of the replication data:

O Comparison of Kaplan-Meier survival curves between vehicle and I-BET151-treated mice using the Log-rank Mantel-Cox test.

- Meta-analysis of effect sizes:

Compute the effect sizes of each comparison, compare them against the effect size in the original paper, and use a random effects meta-analytic approach to combine the original and replication effects, which will be presented as a forest plot.

Known differences from the original study

The original study conditioned the recipient mice with a sublethal dose of radiation (300 cGy) prior to injection of MV4;11 cells. The replication attempt will use a single dose of busulfan, which has been reported to be comparable for human cell engraftment in NOD-SCID mice (RobertRichard et al., 2006). The original study counted PB cells using a SciVet abc machine, while the replication attempt will include CountBright absolute counting beads to determine the absolute number of human leukemia cells in each mouse after treatment. The original study lysed red blood cells from samples using Red Blood Cell Lysis Buffer, while the replication attempt will use ammonium chloride solution while performing HLA-A,B,C and 7-AAD analysis. For analysis of leukemia burden using CountBright absolute counting beads, the cells will be lysed using $1 \times D B$ Lysis Buffer during manufacturer's instructions. All known differences are listed in the materials and reagents section above with the originally used item listed in the comments section. All differences have the same capabilities as the original and are not expected to alter the experimental design.

Provisions for quality control

The cell lines used in this experiment will undergo STR profiling to confirm their identity and will be sent for mycoplasma testing to ensure there is no contamination. Additionally, cells used for xenograft injection will be screened against a Rodent Pathogen Panel to ensure no contamination prior to injection. The animals will be randomized prior to treatment. The apoptotic marker dye 7AAD will be used to exclude populations of dead or dying cells from analysis and an isotype control antibody will be used to confirm the specificity of the HLA-A,B,C antibody. All of the raw data will be uploaded to the project page on the OSF (https://osf.io/hcqqy) and made publically available.

\section{Power calculations}

For additional details on power calculations, please see analysis scripts and associated files on the Open Science Framework:

https://osf.io/bdk6c/.

\section{Protocol 1}

Not applicable.

\section{Protocol 2}

Summary of original data reported in Figures 2A, S11A, and S11B:

\begin{tabular}{lc} 
Cell line & IC $_{50}$ \\
\hline K562 cells $(-M L L)$ & $>100 \mu \mathrm{M}$ \\
\hline MV4;11 cells $(+M L L)$ & $26 \mathrm{nM}$
\end{tabular}


The original data do not indicate the error associated with multiple biological replicates. To identify a suitable sample size, power calculations were performed using different levels of relative variance.

Test family

- Two-tailed t-test, difference between two independent mean values, alpha error $=0.05$.

'Power calculations' performed with G*Power software, version 3.1.7 (Faul et al., 2007).

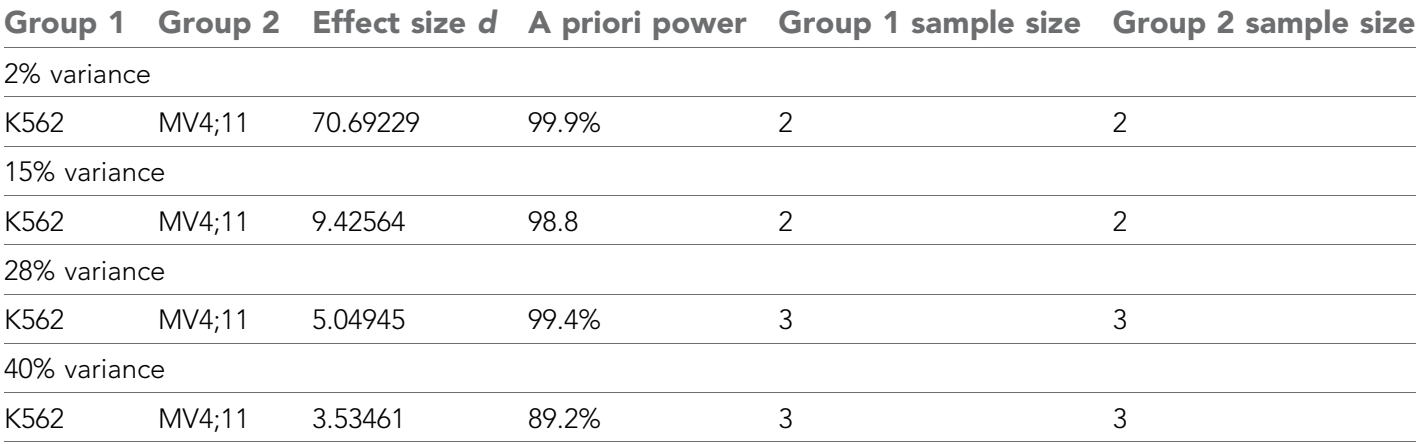

In order to produce quantitative replication data, we will run the experiment three times. Each time we will determine the $\mathrm{IC}_{50}$. The three replicates and the original reported value will be checked to see if the original value is an outlier using Grubb's test (with a significance level of 0.05). If the original value is detected as an outlier it will not be included with the replication replicates to determine the standard deviation of $\mathrm{IC}_{50}$ values, otherwise it will be included in the standard deviation calculation. The calculated standard deviation will be combined with the reported value from the original study to simulate the original effect size. We will use this simulated effect size to determine the number of replicates necessary to reach a power of at least $80 \%$. We will then perform additional replicates, if required, to ensure that the experiment has more than $80 \%$ power to detect the original effect.

\section{Protocol 3}

Summary of original data estimated from graph reported in Figure 3D:

\begin{tabular}{lllll} 
Cell line & Treatment & Mean & Stdev & N \\
\hline K562 cells $(-M L L)$ & DMSO & 1 & 0 & 3 \\
\cline { 2 - 5 } & I-BET151 & 0.22 & 0.03 & 3 \\
\hline MV4;11 cells (+MLL) & DMSO & 1 & 0 & 3 \\
\cline { 2 - 5 } & I-BET151 & 0.935 & 0.05 & 3 \\
\hline
\end{tabular}

\section{Test family}

- Two-tailed t-test, difference between two independent mean values, Bonferroni's correction: alpha error $=0.01667$.

'Power calculations' performed with G*Power software, version 3.1.7 (Faul et al., 2007).

\begin{tabular}{|c|c|c|c|c|c|}
\hline Group 1 & Group 2 & Effect size $d$ & $\begin{array}{l}\text { A priori } \\
\text { power }\end{array}$ & $\begin{array}{l}\text { Group } 1 \\
\text { sample size }\end{array}$ & $\begin{array}{l}\text { Group } 2 \\
\text { sample size }\end{array}$ \\
\hline MV4;11, I-BET151 treated & K562, I-BET151 treated & 17.34130 & $99.3 \% *$ & $2^{\star}$ & $2^{\star}$ \\
\hline
\end{tabular}

*Three samples per group will be used based on the other planned tests making the power $99.9 \%$. 


\section{Test family}

- Two-tailed t-test, difference from constant (one sample case), Bonferroni's correction: alpha error $=0.01667$.

'Power calculations' performed with G*Power software, version 3.1.7 (Faul et al., 2007).

\begin{tabular}{|c|c|c|c|c|c|}
\hline Group 1 & Group 2 & $\begin{array}{l}\text { Effect } \\
\text { size } d\end{array}$ & A priori power & $\begin{array}{l}\text { Group } 1 \\
\text { sample size }\end{array}$ & $\begin{array}{l}\text { Group } 2 \\
\text { sample size }\end{array}$ \\
\hline MV4;11, DMSO treated & MV4;11, I-BET151 treated & 26.000 & $99.9 \%$ & 3 & 3 \\
\hline
\end{tabular}

\section{Test family}

- Two-tailed t-test, difference from constant (one sample case), Bonferroni's correction: alpha error $=0.01667$.

Sensitivity calculations performed with G*Power software, version 3.1.7 (Faul et al., 2007).

\begin{tabular}{|c|c|c|c|c|c|}
\hline Group 1 & Group 2 & Detectable effect size $d$ & A priori power & Group 1 sample size & Group 2 sample size \\
\hline K562, DMSO treated & K562, I-BET151 treated & $5.66748^{\star}$ & $80.0 \%$ & $3^{\star}$ & $3^{\star}$ \\
\hline
\end{tabular}

*Since the original comparison was not statistically significant. This is the effect size that can be detected with $80 \%$ power and the indicated sample size. Unlike the above power calculations, the aim of this sensitivity calculation is not to detect the original effect size, but to understand what effect size could be detected. The original effect size is 1.300 .

\section{Protocol 4}

The law of diminishing return was used to determine the sample size for assessment of MTD (Charan and Kantharia, 2013).

- $\mathrm{E}=$ Total number of animals - Total number of groups.

\begin{tabular}{lll} 
Number of treatment groups & Total sample size with $E=10$ & Total sample size with $E=20$ \\
\hline 4 & $14^{\star}$ & $24^{\star}$
\end{tabular}

*To keep animals per group balanced 16 (4 per group), 20 (5 per group), or 24 (6 per group) total samples keeps E between 10 and 20. 20 total animals (5 per group) will be used to account for any potential exclusion.

\section{Protocol 5}

Summary of original data estimated from Kaplan-Meier graph reported in Figure 4B:

\begin{tabular}{lllll} 
Treatment group & Median survival & Hazard ratio (to vehicle control) & N & Censoring rate (\# censored/day) \\
\hline Vehicle-treated mice & 14 days & N/A & 5 & 0 \\
\hline I-BET151-treated mice & N/A & 0.09687 & 5 & $0.09524^{\star}$
\end{tabular}

*Two mice were censored from the I-BET151 cohort during the 21-day treatment period. For the power calculations, the censoring rate was divided in half since the calculation assumes the censoring rate is equal for both groups.

\section{Test family}

- Log-rank (Mantel-Cox) test: alpha error $=0.05$. 
'Power calculations' performed with the Sample Size Calculator hosted by the UCSF Clinical and Translational Science Institute (Schoenfeld, 1983).

\begin{tabular}{llllllll} 
Group 1 & Group 2 & Treatment duration & A priori power & $\begin{array}{l}\text { Group } 1 \text { total } \\
\text { events needed }\end{array}$ & $\begin{array}{l}\text { Group } 1 \\
\text { sample size }\end{array}$ & $\begin{array}{l}\text { Group } 2 \text { total } \\
\text { events needed }\end{array}$ & $\begin{array}{l}\text { Group } 2 \\
\text { sample size }\end{array}$ \\
\hline Vehicle & I-BET151 & 21 days & $80.0 \%$ & $5^{*}$ & $12^{*}$ & $1^{\star}$ & $12^{\star}$
\end{tabular}

*14 per group will be used to account for a potential higher censoring rate, or exclusion.

\section{Acknowledgements}

The Reproducibility Project: Cancer Biology core team would like to thank the original authors, in particular Mark Dawson for generously sharing critical information to ensure the fidelity and quality of this replication attempt. We thank Courtney Soderberg at the Center for Open Science for assistance with statistical analyses. We would also like to thank the following companies for generously donating reagents to the Reproducibility Project: Cancer Biology; American Type Culture Collection (ATCC), Applied Biological Materials, BioLegend, Charles River Laboratories, Corning Incorporated, DDC Medical, EMD Millipore, Harlan Laboratories, LI-COR Biosciences, Mirus Bio, Novus Biologicals, Sigma-Aldrich, and System Biosciences (SBI).

\section{Additional information}

Group author details

\section{Reproducibility Project: Cancer Biology}

Elizabeth lorns: Science Exchange, Palo Alto, California; William Gunn: Mendeley, London, United Kingdom; Fraser Tan: Science Exchange, Palo Alto, California; Joelle Lomax: Science Exchange, Palo Alto, California; Nicole Perfito: Science Exchange, Palo Alto, California; Timothy Errington: Center for Open Science, Charlottesville, Virginia

Competing interests

JJF: ProNovus Bioscience is a Science Exchange associated laboratory. AK: ProNovus Bioscience is a Science Exchange associated laboratory. XS: Stem Cell and Xenograft Core, University of Pennsylvania Perelman School of Medicine is a Science Exchange associated laboratory. GD-D: Stem Cell and Xenograft Core, University of Pennsylvania Perelman School of Medicine is a Science Exchange associated laboratory. RP:CB: El, FT, JL, and NP: Employed by and hold shares in Science Exchange Inc. The other authors declare that no competing interests exist.

Funding

Funder

Author

Laura and John Arnold

Reproducibility Project: Cancer

Foundation Biology

The Reproducibility Project: Cancer Biology is funded by the Laura and John Arnold Foundation, provided to the Center for Open Science in collaboration with Science Exchange. The funder had no role in study design or the decision to submit the work for publication.

Author contributions

JJF, AK, XS, GD-D, MG, KO, Drafting or revising the article; RP:CB, Conception and design, Drafting or revising the article

\section{Additional files}

Supplementary file

- Supplementary file 1. Mouse Health Scoring System.

DOI: 10.7554/eLife.08997.002 


\section{References}

Chaidos A, Caputo V, Gouvedenou K, Liu B, Marigo I, Chaudhry MS, Rotolo A, Tough DF, Smithers NN, Bassil AK, Chapman TD, Harker NR, Barbash O, Tummino P, Al-Mahdi N, Haynes AC, Cutler L, Le B, Rahemtulla A, Roberts I, Kleijnen M, Witherington JJ, Parr NJ, Prinjha RK, Karadimitris A. 2014. Potent antimyeloma activity of the novel bromodomain inhibitors I-BET151 and I-BET762. Blood 123:697-705. doi: 10.1182/blood-2013-01-478420.

Charan J, Kantharia ND. 2013. How to calculate sample size in animal studies? Journal of Pharmacology \& Pharmacotherapeutics 4:303-306. doi: 10.4103/0976-500X.119726.

Cooke KR, Kobzik L, Martin TR, Brewer J, Delmonte J Jr, Crawford JM, Ferrara JL. 1996. An experimental model of idiopathic pneumonia syndrome after bone marrow transplantation: I. The roles of minor $\mathrm{H}$ antigens and endotoxin. Blood 88:3230-3239.

Cory S, Huang DC, Adams JM. 2003. The Bcl-2 family: roles in cell survival and oncogenesis. Oncogene 22: 8590-8607. doi: 10.1038/sj.onc.1207102.

Darnell JE Jr. 2002. Transcription factors as targets for cancer therapy. Nature Reviews. Cancer 2:740-749. doi: 10. 1038/nrc906.

Dawson MA, Gudgin EJ, Horton SJ, Giotopoulos G, Meduri E, Robson S, Cannizzaro E, Osaki H, Wiese M, Putwain S, Fong CY, Grove C, Craig J, Dittmann A, Lugo D, Jeffrey P, Drewes G, Lee K, Bullinger L, Prinjha RK, Kouzarides T, Vassiliou GS, Huntly BJ. 2014. Recurrent mutations, including NPM1c, activate a BRD4dependent core transcriptional program in acute myeloid leukemia. Leukemia 28:311-320. doi: 10.1038/leu. 2013.338.

Dawson MA, Prinjha RK, Dittmann A, Giotopoulos G, Bantscheff M, Chan WI, Robson SC, Chung CW, Hopf C, Savitski MM, Huthmacher C, Gudgin E, Lugo D, Beinke S, Chapman TD, Roberts EJ, Soden PE, Auger KR, Mirguet O, Doehner K, Delwel R, Burnett AK, Jeffrey P, Drewes G, Lee K, Huntly BJ, Kouzarides T. 2011. Inhibition of BET recruitment to chromatin as an effective treatment for MLL-fusion leukaemia. Nature 478 : 529-533. doi: 10.1038/nature10509.

Delmore JE, Issa GC, Lemieux ME, Rahl PB, Shi J, Jacobs HM, Kastritis E, Gilpatrick T, Paranal RM, Qi J, Chesi M, Schinzel AC, McKeown MR, Heffernan TP, Vakoc CR, Bergsagel PL, Ghobrial IM, Richardson PG, Young RA, Hahn WC, Anderson KC, Kung AL, Bradner JE, Mitsiades CS. 2011. BET bromodomain inhibition as a therapeutic strategy to target c-Myc. Cell 146:904-917. doi: 10.1016/j.cell.2011.08.017.

Dey A, Nishiyama A, Karpova T, McNally J, Ozato K. 2009. Brd4 marks select genes on mitotic chromatin and directs postmitotic transcription. Molecular Biology of the Cell 20:4899-4909. doi: 10.1091/mbc.E09-05-0380.

Errington TM, lorns E, Gunn W, Tan FE, Lomax J, Nosek BA. 2014. An open investigation of the reproducibility of cancer biology research. eLife 3:e04333. doi: 10.7554/eLife.04333.

Faul F, Erdfelder E, Lang AG, Buchner A. 2007. G*Power 3: a flexible statistical power analysis program for the social, behavioral, and biomedical sciences. Behavior Research Methods 39:175-191. doi: 10.3758/BF03193146.

Gallagher SJ, Mijatov B, Gunatilake D, Tiffen JC, Gowrishankar K, Jin L, Pupo GM, Cullinane C, Prinjha RK, Smithers N, McArthur GA, Rizos H, Hersey P. 2014. The epigenetic regulator I-BET151 induces BIM-dependent apoptosis and cell cycle arrest of human melanoma cells. The Journal of Investigative Dermatology 134: 2795-2805. doi: 10.1038/jid.2014.243.

LeRoy G, Rickards B, Flint SJ. 2008. The double bromodomain proteins Brd2 and Brd3 couple histone acetylation to transcription. Molecular Cell 30:51-60. doi: 10.1016/j.molcel.2008.01.018.

Long J, Li B, Rodriguez-Blanco J, Pastori C, Volmar CH, Wahlestedt C, Capobianco A, Bai F, Pei XH, Ayad NG, Robbins DJ. 2014. The BET bromodomain inhibitor i-BET151 acts downstream of smoothened protein to abrogate the growth of hedgehog protein-driven cancers. The Journal of Biological Chemistry 289:35494-35502. doi: 10.1074/jbc.M114.595348.

Lopes de Menezes DE, Peng J, Garrett EN, Louie SG, Lee SH, Wiesmann M, Tang Y, Shephard L, Goldbeck C, Oei Y, Ye H, Aukerman SL, Heise C. 2005. CHIR-258: a potent inhibitor of FLT3 kinase in experimental tumor xenograft models of human acute myelogenous leukemia. Clinical Cancer Research 11:5281-5291. doi: 10.1158/ 1078-0432.CCR-05-0358.

Marschalek R. 2010. Mixed lineage leukemia: roles in human malignancies and potential therapy. The FEBS Journal 277:1822-1831. doi: 10.1111/j.1742-4658.2010.07608.x.

Mertz JA, Conery AR, Bryant BM, Sandy P, Balasubramanian S, Mele DA, Bergeron L, Sims RJ III. 2011. Targeting MYC dependence in cancer by inhibiting BET bromodomains. Proceedings of the National Academy of Sciences of USA 108:16669-16674. doi: 10.1073/pnas.1108190108.

Meyer C, Kowarz E, Hofmann J, Renneville A, Zuna J, Trka J, Ben Abdelali R, Macintyre E, De Braekeleer E, De Braekeleer M, Delabesse E, de Oliveira MP, Cave H, Clappier E, van Dongen JJ, Balgobind BV, van den HeuvelEibrink MM, Beverloo HB, Panzer-Grumayer R, Teigler-Schlegel A, Harbott J, Kjeldsen E, Schnittger S, Koehl U, Gruhn B, Heidenreich O, Chan LC, Yip SF, Krzywinski M, Eckert C, Moricke A, Schrappe M, Alonso CN, Schafer BW, Krauter J, Lee DA, Zur Stadt U, Te Kronnie G, Sutton R, Izraeli S, Trakhtenbrot L, Lo Nigro L, Tsaur G, Fechina L, Szczepanski T, Strehl S, Ilencikova D, Molkentin M, Burmeister T, Dingermann T, Klingebiel T, Marschalek R. 2009. New insights to the MLL recombinome of acute leukemias. Leukemia 23:1490-1499. doi: 10. 1038/leu.2009.33.

Mueller D, Garcia-Cuellar MP, Bach C, Buhl S, Maethner E, Slany RK. 2009. Misguided transcriptional elongation causes mixed lineage leukemia. PLOS Biology 7:e1000249. doi: 10.1371/journal.pbio.1000249.

Nicodeme E, Jeffrey KL, Schaefer U, Beinke S, Dewell S, Chung CW, Chandwani R, Marazzi I, Wilson P, Coste H, White J, Kirilovsky J, Rice CM, Lora JM, Prinjha RK, Lee K, Tarakhovsky A. 2010. Suppression of inflammation by a synthetic histone mimic. Nature 468:1119-1123. doi: 10.1038/nature09589. 
O'Farrell AM, Abrams TJ, Yuen HA, Ngai TJ, Louie SG, Yee KW, Wong LM, Hong W, Lee LB, Town A, Smolich BD, Manning WC, Murray LJ, Heinrich MC, Cherrington JM. 2003. SU11248 is a novel FLT3 tyrosine kinase inhibitor with potent activity in vitro and in vivo. Blood 101:3597-3605. doi: 10.1182/blood-2002-07-2307.

Pastori C, Daniel M, Penas C, Volmar CH, Johnstone AL, Brothers SP, Graham RM, Allen B, Sarkaria JN, Komotar RJ, Wahlestedt C, Ayad NG. 2014. BET bromodomain proteins are required for glioblastoma cell proliferation. Epigenetics 9:611-620. doi: 10.4161/epi.27906.

Robert-Richard E, Ged C, Ortet J, Santarelli X, Lamrissi-Garcia I, de Verneuil H, Mazurier F. 2006. Human cell engraftment after busulfan or irradiation conditioning of NOD/SCID mice. Haematologica 91:1384.

Schoenfeld DA. 1983. Sample-size formula for the proportional-hazards regression model. Biometrics 39:499-503. doi: $10.2307 / 2531021$.

Slany RK. 2009. The molecular biology of mixed lineage leukemia. Haematologica 94:984-993. doi: 10.3324/ haematol.2008.002436.

Smith E, Lin C, Shilatifard A. 2011. The super elongation complex (SEC) and MLL in development and disease. Genes \& Development 25:661-672. doi: 10.1101/gad.2015411.

Tamai H, Inokuchi K. 2010. 11q23/MLL acute leukemia: update of clinical aspects. Journal of Clinical and Experimental Hematopathology 50:91-98. doi: 10.3960/jslrt.50.91.

Tolani B, Gopalakrishnan R, Punj V, Matta H, Chaudhary PM. 2014. Targeting Myc in KSHV-associated primary effusion lymphoma with BET bromodomain inhibitors. Oncogene 33:2928-2937. doi: 10.1038/onc.2013.242.

Wu SY, Chiang CM. 2007. The double bromodomain-containing chromatin adaptor Brd4 and transcriptional regulation. The Journal of Biological Chemistry 282:13141-13145. doi: 10.1074/jbc.R700001200.

Wyspianska BS, Bannister AJ, Barbieri I, Nangalia J, Godfrey A, Calero-Nieto FJ, Robson S, Rioja I, Li J, Wiese M, Cannizzaro E, Dawson MA, Huntly B, Prinjha RK, Green AR, Gottgens B, Kouzarides T. 2014. BET protein inhibition shows efficacy against JAK2V617F-driven neoplasms. Leukemia 28:88-97. doi: 10.1038/leu.2013.234.

Zuber J, Shi J, Wang E, Rappaport AR, Herrmann H, Sison EA, Magoon D, Qi J, Blatt K, Wunderlich M, Taylor MJ, Johns C, Chicas A, Mulloy JC, Kogan SC, Brown P, Valent P, Bradner JE, Lowe SW, Vakoc CR. 2011. RNAi screen identifies Brd4 as a therapeutic target in acute myeloid leukaemia. Nature 478:524-528. doi: 10.1038/ nature10334. 